Article

\title{
The Well(s) of Knowledge: The Decoding of Sustainability Claims in the UK and in Greece
}

\author{
Panayiota J. Alevizou ${ }^{1, *}$, Caroline J. Oates ${ }^{1}$ and Seonaidh McDonald ${ }^{2}$ \\ 1 Department of Marketing and Cultural Industries University of Sheffield, Conduit Road, \\ Sheffield S10 1FL, UK; E-Mail: c.j.oates@sheffield.ac.uk \\ 2 Aberdeen Business School, Robert Gordon University, Garthdee Road, Aberdeen AB10 7QE, UK; \\ E-Mail: s.mcdonald@rgu.ac.uk
}

* Author to whom correspondence should be addressed; E-Mail: p.j.alevizou@sheffield.ac.uk; Tel.: +44-114-222-3423.

Academic Editor: Marc A. Rosen

Received: 31 March 2015 / Accepted: 24 June 2015 / Published: 3 July 2015

\begin{abstract}
Sustainability claims have existed on fast moving consumer goods (FMCGs) for over four decades and there is evidence that they are increasing. Research suggests that consumers have a low level of knowledge and understanding of such labels. It has been found that environmental and labelling knowledge may influence consumption behaviour but the findings so far have been inconsistent. Furthermore, the issue of knowledge and particularly sense making of the variety of claims found on FMCGs today is somewhat under researched. In this paper we investigate the types of knowledge consumers draw upon in order to decode and make sense of different types of labels across two countries. We carried out a qualitative study in the UK and Greece with 12 focus groups and utilised concepts of knowledge to investigate consumer decoding of labelling. We found that overall consumers have limited labelling knowledge and understanding even though their environmental knowledge may vary. This limited labelling knowledge makes consumers feel unsettled and unsure about their shopping decisions. Finally, we identified areas where consumers demonstrated limited knowledge and requested further information and education. This has important implications for companies, marketers, and policy makers if sustainability claims are to promote and support sustainable consumption.
\end{abstract}

Keywords: labelling; environmental knowledge; FMCGs; on-pack sustainability claims; decoding; UK; Greece 


\section{Introduction}

Social and environmental issues have received increased attention especially in terms of their influence on both sustainable consumption [1-5] and sustainable production [6-9]. Consumers demand more environmentally sound products and are willing to pay the price [10-13]. Companies respond to these demands [11] and differentiate their products with on-pack green claims, which assist greener consumer decisions. This has resulted in the proliferation of on-pack claims and information [14], which range from mandatory labelling schemes, voluntary labelling initiatives, to endorsements [14]. Belz and Peattie [8] argue that labelling has two important roles: on the one hand communicating aspects of sustainable consumption to consumers, and on the other hand influencing consumer behaviour, by being able to make a more informed decision. Thus, the aim of environmental labelling is to promote and support sustainable consumption [15], and there has been a rise in research on different types of on-pack green labelling [2,16-19]. In this manner, the terminology of claims and labels in the literature has seen noticeable changes over the past decades. In the 1980s and 1990s the term "green claims" was used most often $[1,2,19]$, and predominantly referred to environmental attributes of the products, such as whether they were recyclable or CFC-free (CFC is a short name for Chlorofluorocarbon, an ozone-depleting compound that has been banned from use in many FMCGs). Since then, terms such as social and cause related marketing claims [20], eco labels [17,18], environmental claims [16,21,22], and sustainability labels [8] have emerged in the labelling literature. Additionally, Harrison et al. [23] state that some compulsory labels can be of accidental value to the ethical consumer. For instance, UK food labelling regulations, which require ingredients and country of origin data to be shown, are useful to vegetarians and vegans and those boycotting particular countries or trying to avoid food miles [23]. This not only highlights the importance of labelling as a market-based tool but also its complexity.

The emergence of on-pack labelling claims led to a call for some kind of categorisation, which was attempted by the International Organisation for Standardisation (ISO) [17]:

- Type I eco labels: multi-criteria third-party programs (e.g., EU eco label);

- Type II claims: self-declared environmental claims (e.g., CFC Free);

- Type III declarations: provide quantified information in environmental product declarations (e.g., energy rating reports).

However, Rubik and Frankl [17] highlight the ISO's efforts because the classification does not encompass the whole labelling landscape and omits instruments such as obligatory labels, test reports, trademarks, and other aspects, such as social affairs including fair trade [17,23]. As a result, consumers have been exposed to a variety of new, unfamiliar technical terms, which make the decoding process of these claims challenging. Nocella et al. [24] mention that consumers are able to evaluate some product attributes, such as price and organoleptic characteristics through their own direct experience. However, this does not seem to be the case with the so called "credence attributes" (e.g., animal welfare) which are more difficult for consumers to evaluate due to their intangible nature [24]. Whilst past research has focused on the importance of environmental knowledge in consumption behaviour, results have not been conclusive. Peattie [25] states that consumers who are knowledgeable about environmental problems are motivated towards green consumer behaviour, however the author also mentions that this has not always been the case. Specifically, various authors [26-29] have examined the relationship between 
environmental knowledge and behaviour, but have been unable to identify a clear link between these constructs, which according to Peattie [25] can be attributed to the difficulty in measuring environmental knowledge and the inconsistency in translating it to actual consumer behaviour. There have been different categories or types of environmental knowledge in the literature such as subjective and objective [30] or concrete and abstract [31]. The issue of knowledge when consumers decode on-pack claims has recently gained attention in the literature [24]. However, there is a research gap in terms of the types of knowledge that consumers use during the decoding process, which is addressed in this article. If claims are to support sustainable consumption, consumers first need to be aware of them and second understand them. Thus, this article addresses the following research questions:

What strategies do consumers use to decode sustainability claims on fast moving consumer goods (FMCGs)?

What types of knowledge do they use when making sense of sustainability claims?

This paper utilises a qualitative and a cross national approach in order to gain a better understanding of the factors that influence consumers' environmental knowledge of claims that exist within the current market environment. This article uses the term sustainability claims (SC) in a loose sense to include the ISO's classification of labels, as well as other ethical and social claims found on FMCGs. The following sections provide a brief literature review and outline the methodology used in this study, before presenting the findings and implications.

\section{Background}

\subsection{Environmental Knowledge and Eco Literacy}

Environmental knowledge within the literature is often referred to as environmental or ecological literacy. This said, within academia eco literacy is seen as incorporating more than environmental knowledge. Fryxell and Lo [32] mention that environmental (or eco) literacy carries strong normative implications and embraces deep spiritual elements [33]. On the other hand, Orr [34] defines eco literary by emphasising what the term literacy is, namely "the ability to read and is a mark of education and therefore a person who is literate can understand what is written and place it into a context of meaning" (p. ix). Thus, for Orr [34], eco literacy is a sense of wonder. Golley [33] expands on Orr's [34] definition and argues that environmental literacy begins with experiencing the environment. Golley [33] indicates that ecological literacy is more than knowing the names of the organisms and understanding geomorphology, rather it incorporates "feeling the landscape through all the senses" [33] (p. ix). In other words, the author argues that "experience triggers environmental literacy" [...] "and to build environmental literacy it is necessary to go beyond books and libraries and experience nature directly" [33] (p. x). Morrone et al. [35] concur with this view and highlight that environmental literacy involves more than just knowledge about environmental issues. In a similar manner, Disinger and Roth [36] suggest that a literate individual combines knowledge with values, which leads to action [35]. Thus, it could be said that the four goals of environmental education are: "knowledge about ecological concepts, conceptual awareness about how behaviour affects the environment, knowledge and skills for issue investigation and evaluation and environmental action skills" [37,38]. In summary, although environmental and ecological literacy have been used to refer to environmental knowledge, the terms are different in nature. 
The literature indicates that ecological literacy is the umbrella term of which environmental knowledge is one part. Due to the nature of this study, the focus will be on the more inclusive term of ecological literacy when investigating consumers' environmental knowledge of sustainability claims.

\subsection{Environmental Knowledge and Classifications}

Knowledge is a complex concept that affects the way consumers gather and organize information and determine how they evaluate products and services. Knowledge in more green terms is defined as one's ability to identify a number of ecologically-related symbols, concepts, and behaviour [39]. Environmental knowledge is characterised as a general knowledge of facts, concepts and relationships concerning the natural environment and its major ecosystems [32]. The authors [32] explain that environmental knowledge involves "what people know about the environment, key relationships leading to environmental aspects or impacts, an appreciation of 'whole systems', and collective responsibilities necessary for sustainable development" [32] (p. 48). Environmental knowledge refers to "how much" an individual knows about environmental issues [40]. The knowledge concept has attracted academics for several decades, with various theories emerging that focus on attitudes and environmental behaviour, such as Ajzen and Fishbein's [41] theory of planned behaviour. The link between environmental knowledge and pro-environmental behaviour has been debated heavily within the literature and brought forward two camps, one of which advocates a strong relationship between the concepts [26,42,43], and another which believes that whilst there is a link, this relationship is weak in nature [27,29,31,32,44]. Looking at the literature closely, it becomes apparent that the two most commonly cited constructs that influence consumer behaviour are the consumer's environmental attitudes and knowledge [45]. It should be noted that a common denominator in most studies remains the fact that environmental knowledge alone does not equate to green purchases. Thus, it appears that the link between consumers' knowledge about the environment and their beliefs, attitudes and behaviour has rarely been consistent or straightforward $[25,31,42,46]$. Specifically studies have classified environmental knowledge and have looked at how these classifications can influence consumer environmental behaviour.

Schahn and Holzer [31], for instance, focused on the role of knowledge, gender and background variables of the individual's environmental concern. Within their work the authors use the term abstract knowledge to gain information on questions that are of a more descriptive nature, for example "ecology is best described as..." (p.772) and the term concrete knowledge to measure to what extent and how consumers apply information on environmental protection, by asking questions such as "how can you save water...”? (p.772). A key contribution of their study is that neither of the knowledge scales correlated significantly with self-reported behaviour. Nevertheless, their results demonstrate that knowledge plays a role in environmentally responsible behaviour despite its low direct correlations with the variable [31]. Cheah and Phau [30] argue that conceptually, consumer knowledge can be divided into two components: objective and subjective knowledge. The authors mention that objective knowledge refers to the content and organization of knowledge (factual knowledge) that is stored in one's memory. Thus, it refers to what an individual actually knows about a type of product/issue/object [30]. On the other hand, subjective knowledge refers to the individual's perceptions or assessments of what and how much they know about a product/issue/object $[47,48]$. 
In summary, the literature on environmental knowledge suggests two main classifications of environmental knowledge (abstract and concrete; objective and subjective). However, in the marketing literature, scholars particularly refer to knowledge in relation to a brand, a product and recently labels.

\subsection{Labelling Knowledge}

In the marketing literature knowledge of labels has received attention [5,49-51]. Past research suggested that consumers prefer products that have a familiar seal on their packaging [52]. However, whilst consumers attribute high credibility to familiar seals, they seem to be unaware of the meaning and implications of these seals [52]. This implies that in order to understand the actual meaning of the seal or label attached to a product, information and knowledge is required to decode the message. In a similar manner, Hoek et al. [5] have pointed out that consumers utilise labels, seals and certifications as heuristic tools to simplify their decision-making processes. According to the authors, this is common practice in the retail setting for FMCGs where reflection on information is limited. Thøgersen [49] agrees with previous findings and proposes a vicious circle, as knowing a label is a prerequisite for using it in a decision-making process, however in order to gain benefits from the label and use it correctly, a prerequisite is that the individual knows the meaning of the label. D'Souza et al. [51] and Pederson and Neergaard [50] found that this vicious circle continues as consumers lack knowledge of the types of labelling procedure adopted by organisations. In their study, D’Souza et al. [53] also found that consumers appear to have poor knowledge regarding labels and label types. Additionally, they found that consumers are only aware of generic labelling using terms such as "biodegradable”, "phosphate free" and "recyclable” which are Type II claims.

Furthermore, various authors [54-56] have argued that the complexity and low level of understanding of environmental issues communicated to consumers for example via labelling or other programs may lead to confusion and even mislead them in their purchase decision making. Specifically, Polonsky et al. [56] argue that some environmental issues such as carbon offsets are considerably too complex for consumers to understand and therefore incorporate into their purchasing decisions. The authors pose a noteworthy question of whether consumer behaviour in relation to carbon offsets and more generally the environment is influenced by their knowledge of the issue. Polonsky et al. [56] offer an example of how consumers lacking specific environmental knowledge may be confused and even misled in their purchasing decisions. They mention that consumers may believe that a firm investing in planting trees will reduce their carbon footprint, whereas, in reality, carbon savings will only occur in the future, assuming the trees grow to maturity.

It has been argued that knowledge of environmental issues tends to create not only awareness for particular brands, but also raises positive attitudes towards these brands, which is enhanced through the use of environmental labels [51]. D’Souza et al. [51] argue that environmental knowledge evolves in two forms: on the one hand consumers have to be educated to understand the general impact of the product on the environment, and on the other hand consumers have to gain the knowledge that products are produced in an environmentally friendly way. In addition, D’Souza et al. [51] argue that despite the limited number of studies, the conclusions point towards general difficulties for consumers to explain environmental problems related to the products, the distinction between "green products" and conventional products or the communication of the actual benefits of a supposed superior or eco-labelled 
product. Additionally, the authors note that consumers lack knowledge of the types of labelling procedures adopted by organisations. These findings concur with previous studies stressing that consumer awareness of broad environmental issues generally do not coincide with their understanding of specific environmental claims [51]. Thus, this study addresses the gap in the literature by exploring environmental knowledge from a marketing point of view and by investigating whether the types of knowledge identified allow consumers to decode sustainability claims. In other words instead of trying to measure the level of consumer knowledge we focus on exploring the types of knowledge consumers use to make sense of the various labels.

In summary, past research, whilst instructive, has predominantly focused on measuring the level of labelling and environmental knowledge consumers have, without looking at the process of decoding and sense making. The majority of these studies are quantitative in nature and highlight that consumers lack awareness and knowledge of the impact of products and of labelling schemes. Thus, this study by taking a qualitative approach seeks to explore whether additional layers of knowledge are utilised by consumers and most importantly how consumers make sense of the variety of labels in the market, by bringing together concepts of different layers and types of knowledge.

\section{Methodology}

This article is based on a qualitative cross-cultural methodology and examines consumer perceptions in order to better understand human and social activity. Cross-cultural research has increased in importance within an international context [57] and is complemented by the qualitative nature of this study. In order to gain rich data sets and understand consumers' perceptions of the environmental information displayed on FMCGs focus groups were chosen as a research method [58]. In total, 12 focus groups were carried out in the UK and Greece, each of which lasted two and a half hours. Participation in the focus groups required consumers to purchase regularly FMCGs. A common experience is essential within focus group discussions as the participants need to be able to discuss events and/or behaviour, in this case purchasing similar products [59]. In order to secure participation of consumers with common experiences we used a screening form and recruited the participants outside FMCG retailers, based on gender, family characteristics, age, and shopping practices (frequency, preferred retailers, etc.).

Each focus group consisted of eight participants, following the suggested good practice [60-62] of recruiting six to nine participants per group, which is seen as ideal and more practical with complex topics [63]. In terms of composition it has been argued that homogenous characteristics are important for successful focus groups [62,63]. Kruger [63] clarifies that homogeneity is sought in terms of occupation, educational level, age, gender or family life cycle. Thus, in order to keep our groups on a country level homogeneous and consistent we selected participants with common in-group characteristics. We specifically recruited:

- One group in each country of pre family male consumers, 20-30 years old, single/married/co-habiting;

- One group in each country of pre family female consumers, 20-30 years old, single/married/ co-habiting;

- One group in each country of male consumers 20-35 years old, married or co-habiting with children under 16 at home; 
- One group in each country of mixed female and male consumers 20-35 years old, married or co-habiting with children under 16 at home;

- One group in each country of female empty nesters, 50-65 years old, single/married/co-habiting;

- One group in each country of mixed male and female empty nesters, 50-65 years old, single/married/co-habiting.

The segmentation criteria mentioned above were set more in terms of securing homogenous groups rather than making assumptions and comparisons based on socio-demographic characteristics. In other words, in this paper we focus on the country level differences and similarities rather than on consumer socio- demographics. For this reason we made sure that our groups were homogeneous in both countries and the composition of each groups was consistent across countries.

The focus groups conducted in Greek were fully transcribed and translated by the principal researcher into English. The study received full ethical approval from the researchers' institution.

Overall the two countries present examples of not only diametrically different levels of policy climate, but also political and market commitment to sustainability. The reason for selecting two countries and within them two different sectors is the fact that sustainability claims (SC) differ significantly from one sector to another and across countries. Whilst the two countries are both governed by EU frameworks the labelling norms differ within the retail sectors. This is an additional way of enhancing comparisons within a national context, of exploring SC rituals and supporting Boström and Klintman's [18] (p.15) argument that "one singular national context does not determine how labelling projects are conducted".

During the focus group sessions, participants were shown various products bearing different kinds of claims. The product categories shown to the participants ranged across toiletries, cosmetics, home care products, personal care products and food. The researchers carefully pre-selected these products from four major UK and Greek retailers, which were monitored for a period of two months each. To explain, the researchers continuously visited the retailers and purchased any FMGCs that were found with an on-pack claim as done in extant research [5,51,64]. The majority of the labels found in Greece were Type II claims whereas in the UK the majority were certifications. At this point and for this paper we did not consider the frequency of the labels found in retailers in both markets but rather focused on the type of label (Type II, certifications, etc.). Overall, a variety of claims were found and shown to consumers. These included Type I eco labels such as the Nordic Swan as it was present in both countries even though green claim guidelines suggest that 'claims need to be relevant to the area where the corresponding environmental impact occurs' (see ISO 14021:5.7). Specifically, the International Standards Organisation (ISO) categorization of green claims (i.e., Type I, Type II, Type III) was employed in order to gain an overall view of consumers' perceptions of different types of claims. Type I (ISO 14024) and Type I-like claims are based on criteria that are set by a third party. With this category of claims, one label may represent a range of environmental issues. The body awarding the label may either be a governmental organisation or a private non-commercial entity. Examples would be the Nordic Swan in Sweden, the EU Daisy or Japan’s Eco-Mark. Type II (ISO 14021) claims are based on self-declaration by manufacturers or retailers. They may appear as symbols, logos, words, pictures or slogans, i.e., “made from X\% recycled material”, “ozone friendly”. Type III (ISO/TR 14025) claims consist of quantified information based on life cycle impacts. 
Data analysis of this study follows in the footsteps of Easterby-Smith et al.'s [65] seven-step guide, which allows for an inductive approach and the emergence of themes and codes. The seven-steps include: familiarisation with the data, which was achieved through continuously listening to the audio recordings and reading through the transcripts; reflection, which enabled the researchers to identify the "so what" question; conceptualisation, whereby themes and codes emerged from the data; linking, which allowed the researchers to create clusters and patterns from the data analysis; re-coding of the data to ensure that the various transcripts were looked at in-depth and no information was missed; cataloguing concepts, which allowed the researchers to identify the key themes and their sub-categories; and finally re-evaluation, which meant refinement of the findings by looking at the transcripts for a last time. In practice the analysis of the focus group discussions was an on-going, reflective, and time-consuming process, which started as soon as the first discussion was conducted. Notes were taken during and after the interview and included important focus group discussion elements such as: post interview discussions with consumers; body language during the discussions; and moderator observations regarding the wider environmental context of the discussions, such as media messages/events mentioned by consumers. The mapping of the discussions was done on a sheet generated from the focus group agenda. It is a flexible approach to coding or open coding [66] which was considered more suitable for this research in order to retain flexibility in dealing with data and allowing exploration of new ideas, meanings and relations. Each interview had a unique sheet/map. After each focus group the new map was reviewed and contrasted with the previous one and this process continued until the final interview. By the time of the last interview the coding process had generated strong themes, patterns and new research issues.

\section{Findings-Decoding the Labels}

\subsection{Eco Labels}

Altogether three Type I eco labels were shown to consumers: the Blue Angel, The Nordic Swan and the EU eco label. Within both country settings consumers were not only less knowledgeable about, but also less aware of Type I eco labels. This can be explained by the low frequency of the labels in both markets as the Nordic Swan is mainly found in the Nordic countries and the Blue Angel is a German label. We decided to include these labels in our study as they were available in both markets.

This low awareness provided various challenges when facilitating discussions on eco labels. The low awareness rate of eco labels in both countries left the consumers with feelings of confusion, frustration, and mistrust. Although, consumers were not aware of these eco labels, they were asked to decode their message as on-pack claims. In order to understand the Type I claims presented consumers resorted to a visual approach, thereby focusing on the wording provided on the label, the visual icon, the product type, the wording and the brand. In both countries consumers recognised the wording of the EU eco label and indicated that this label was an EU award.

I would believe that one [EU Daisy] before I believe the others [Type II claims] because they said, they have received an EU award (UK, male).

When consumers elaborated further on the meaning of the logo they highlighted that "well this here [Type I] seems to be the organisation that is responsible and authorised by the EU in each country to 
control how much these products protect the environment” (UK, female). This however, does not correspond with the EU eco label definition, which indicates that products that have been awarded this eco label have reduced environmental impact.

However, data indicated that consumers were not knowledgeable enough to comment further on the type of award, the context, or the criteria. Instead, they referred to their perceptions of EU regulation/legislation and concluded that this type of label was verified by an EU body. A noticeable finding that emerged was the fact that consumers tried to make sense of the EU Daisy by linking the symbol to other known EU symbols, such as the CE logo, and attempted to make associations. In both countries the EU Daisy was considered more relevant to the local markets than the Blue Angel and the Nordic Swan, which seemed to confuse consumers in terms of the country relevance. Consumers believed that Type I eco labels are "attached to the country of origin". This brought forward a political debate regarding the relevance of an EU award as opposed to a national one. Specifically consumers in both countries questioned the criteria behind the awards and their relation to the different local environmental problems and issues they are addressing.

"You can see for example this product here that is produced in Holland and sold in Greece it has the same package, green claims and all that, so are they implying that we have the same climate with Holland?” (Greece, male).

When focusing on aspects of information provided with the individual logos, several consumers in both countries mentioned that the EU Daisy may be more "official” due to the EU wording. However, they felt that the messages accompanying this label are less educational, in that the underlying environmental message gets lost. In summary, consumers' knowledge of eco labels was limited in both countries. The type of knowledge consumers used in order to make sense of the labels was related to the regulation, to political factors and to the visual/branding aspects of the product and less to the environment.

\subsection{Other Type I Like Labels-Certifications}

The second type of labels that the researchers investigated further is Type-I like certifications. For this purpose, consumers were presented with the following certifications: Fair Trade, Community Trade, The Soil Association, Organic, Forest Stewardship Council (FSC), and Rainforest Alliance. All certifications were shown on relevant FMCGs. The first important finding was that the consumers' label knowledge in the UK was higher than the knowledge of Greek consumers. This could be explained by the popularity and frequency of the labels in the UK market compared to the Greek one. Consumers used their abstract knowledge and thus, decoded the majority of the certifications based on the underlying environmental and social issues such as forest depletion, unsustainable fishing practices in the Mediterranean Sea and unethical labour practices in developing countries. The type of knowledge used in this case was similar in both countries. Data highlighted that the majority of consumers acquired their knowledge about these certifications from the media, with the exception of a minority of consumers, who had a background in environmental sciences.

In the case of Community and Fair Trade logos consumers responded more positively and with substantial abstract knowledge. They discussed the social inequalities in today's global environment and focused on unethical company practices. From the data it became apparent that these claims received 
more interest from the participants than others that were presented in the study. Concrete knowledge in this case came down to purely a supportive or boycotting shopping behaviour.

"Coffee and tea should be fair trade... I always look for the logo... it means that farmers get a better deal..." (UK, female).

Some consumers in the UK brought up the issue of trade-offs and the fact that these types of labels can be "less environmentally friendly" (UK, male).

Consumers indicated that they base their knowledge of community development and Fair Trade issues on information that they had acquired from leaflets distributed by retailers and Fair Trade campaigns displayed in the media. In other words consumers especially in the UK were highly aware of this type of labels due to their high frequency in the UK market as well as to the various awareness and promotional campaigns at the time of the research. Data revealed that consumers discussed labour conditions and community development quite passionately, which justifies the success of these certifications. However, in terms of concrete knowledge they stressed the importance of their shopping behaviour rather than other types of consumer involvement such as reduced consumption. Overall, consumers decoded these certifications by using both abstract and concrete knowledge. What they were unable to distinguish was the difference between the variations of fair trade labels such as fair trade and community trade. It is noteworthy to mention that although consumers in Greece, were not widely aware of these labels, they used abstract knowledge to make sense of them, following the pattern of the UK consumers.

In the case of the FSC logo consumers in both countries used their abstract knowledge and decoded the logo as a positive effort connected to forest depletion. Even though in Greece the logo had limited awareness consumers were very enthusiastic about forest protection and raised the issue of destruction of the country's forests as a key environmental problem that needs attention. Some Greek consumers used their concrete knowledge and mentioned that when shopping for Christmas trees: “...we never get real trees. Never" (Greece, male). Overall, the logo was decoded by using environmental knowledge in both countries and not labelling knowledge.

The organic logo was found in various forms. In the UK consumers were more aware of the Soil Association certification, which was not found in Greece. In the consumers' opinion this logo implies that products meet organic standards. However, they were unsure whether this was a UK or an international logo. A majority of participants used their concrete knowledge when decoding the claim and focused on how producers minimise the environmental effects of their production practices. The issue of pesticides, eco-friendly fertilisers, health, and environmental degradation were topics that received great attention. Various participants connected these labels to tastier food and healthier alternatives.

A noteworthy observation in Greece was the fact that Greek consumers seemed to have a more negative connotation towards organic standards, due to a plethora of certifications in the marketplace combined with negative media attention. This made the decoding process of various organic certifications more challenging for consumers. When discussing these labels, consumers indicated that they distrust these certifications as they believe that all food is grown under the same natural conditions. In this case consumers formed opinions based both on abstract and concrete knowledge. Additionally, the words, "marketing”, “advertising” and "pricing” were mentioned frequently. This was also the case with UK consumers where the issue of increased prices was associated with organic products and 
overshadowed any environmental benefits and associations. It seemed that the media enhanced the negative views associated with organic food in both countries.

“Organic food is not as cracked up as it seems to be really... I read it somewhere...” (UK, male).

The Rainforest Alliance logo was not well-known in either country and consumers used a visual approach to decode the logo. Consumers assumed that the logo was linked to conservation of rainforests and failed to see other aspects of the logo. The knowledge they used was mostly abstract as they lacked concrete knowledge associated with the issue and logo. In Greece only a minority of consumers engaged in a conversation about the logo, which can be explained by the limited label recognition in that country.

\subsection{Company Generated Claims (Type II Claims)}

In both countries consumers were shown a variety of company generated claims, including, but not limited to sustainability, biodegradability claims, recycled/recyclability, compostable, ozone related claims, environmentally friendly messages, company social/environmental action logos, animal testing, and dolphin safe claims. At this stage of the research process the researchers were able to observe increased frustration amongst the consumers, which was directed towards the companies generating these claims, as well as their governmental organisations for the lack of information and guidance.

Data revealed that the claims commonly recognised by consumers were recycled/recyclable claims. Consumers in both countries were able to distinguish between the recyclable and recycled claims. In decoding these claims consumers mainly used their concrete knowledge and talked about their recycling practices and how these logos were relevant in this context. In the UK the majority of consumers believed that there were far too many "recycled" and "recyclable" logos. According to consumers there are "different levels of recyclability". Consumers in both countries did not know the difference between the Mobius Loop and the Green Dot and with their concrete knowledge decoded the claims as the product and/or packaging being recyclable. Consumers in both countries raised the issue of limited regulatory knowledge and requested to be informed about the variations of the logos and their legal underpinnings.

One label that caused heated discussions was the animal testing logo. The logo was found in various colours, forms, and wordings. The wordings in some instances caused various challenges, as some highlighted that although the "product [is] not tested on animals, [...] it is likely that ingredients will have been tested at some time in the past", which disappointed various consumers. This label however was purely decoded based on perceptions related to animal testing company practices and not on actual knowledge about animal testing regulation and practices.

“...I check whether the product is tested on animals or not...and I prefer products that are not...” (Greece, female).

In this case both abstract and concrete knowledge were limited. There was a perception held by a few consumers that if the product is not tested on animals then it is dangerous for human beings. This created debates in the groups and the two opposing views related to the abstract knowledge of animal testing. This indicates that the label allows various interpretations in the way it is presented on some products. Additionally the abstract knowledge connected to the wider animal testing issue was limited and overshadowed by personal opinions of whether products should be tested on animals or not. 
Similarly to the animal testing label, the dolphin safe claim created a level of confusion in both countries. Consumers used abstract knowledge and discussed the marine eco system and the effects of pollution. They also used their concrete knowledge in order to make sense of the logo and discussed fishing practices, sustainable fishing, and the protection of marine life. Both the use of abstract and concrete knowledge varied. On the one hand consumers thought that the product may contain dolphins and on the other hand consumers decoded the label as protecting dolphins. This indicates that the knowledge of the label is limited but the interest in the label and specifically the abstract knowledge behind it is high.

Claims with pictures of the earth, trees, rivers, green colours and animals with inscriptions such as "ozone friendly”, “ecological product”, “earth friendly”, and "environmentally safe” were found on products. However, the mentioned claims were viewed as vague, misleading and a source of mistrust, suspicion and confusion. In decoding these claims consumers used their abstract knowledge as well as their marketing knowledge. By the end of the discussions most consumers labelled Type II claims as marketing gimmicks and pure advertising indicating that at some point along the process environmental knowledge is considered as not relevant and essential for these claims. The word "sustainability" was hard for consumers to decode and define. Consumers could not see the link between sustainability claims and the actual products and saw such claims as "it means protecting the environment" (Greece, male).

A logo that created very negative perceptions is the CFC free logo, which appeared on the most product categories and in the most variations. The CFC free claim was found on aerosol and non-aerosol products, on plastic cups, and on cleaning sponges. Consumers were not all aware of what the abbreviation meant but they decoded the label according to their abstract knowledge about the ozone layer. However many consumers were confused about its meaning “...CFCs it means Care Friendly... of something...” (Greece, male). Other consumers in Greece attributed their limited labelling knowledge to language. "...no one does! We do [not] know their scientific English vocabulary. We do [not] even know the scientific Greek vocabulary...” (Greece, female). The low CFC label knowledge can be attributed to the fact that it was found on a variety of products ranging from aerosol bottles to baby cleaning sponges and straws. Consumers could not understand how a sponge could harm the environment and what the link could be between a sponge and the ozone layer. This underlines the importance of the claim relevance to the product and the sector. The most common answers were that the product is safe and it is not "from the ozone", or that “...companies did not use agents that damage the ozone layer...” or that "the water that it absorbs...and it doesn't get toxic?”. To make things more complicated the logo was also found in various forms and in a few cases with different abbreviations such as CFG and CFS. "It must be a typing mistake since who cares! No one knows CFCs either" (Greece, male). Overall, labelling and concrete knowledge was not used as it was absent. Consumers referred to the market knowledge and looked at the brand, the price and the packaging. It seems that they quickly combined their limited environmental and labelling knowledge with their market/ brand knowledge by making associations between logos and products price and quality.

In summary, consumers had low labelling classification knowledge and in many cases were confused as to whether some Type II claims were referring to the packaging or to the product itself. The overall confusion and mistrust around Type II claims created a negative domino effect on other logos and eco labels. 
"... and how do we know that the recycling sign is true? What makes it different to all of the other 'CFC Free” signs ... and “eco-friendly' signs?” (UK, female).

\section{Discussion and Implications}

A key finding brought forward in this research is that consumers use different sources and types of knowledge in order to decode on-pack sustainability claims. They refer to these sources interchangeably in order to make sense of the explicit and implicit context of the claims. Furthermore, the national/country setting is crucial for consumers' decoding process. As indicated in the findings UK consumers were more aware of certain certifications such as the Fair Trade certification, which they attributed to the UK wide promotion of the label and the underlying cause. In Greece, consumers talked about their limited environmental and labelling awareness and knowledge given the relatively low promotion of such issues by the government and the media. In this case consumers used their market/brand knowledge and the visual characteristics of the product and the label in order to make sense of the underlying message. As a consequence, some labels were interpreted differently and not always in the sense that they were original set out for. This entire process becomes important for marketers if they intend to address the type of knowledge that is required for the successful encoding of their label. Thus, marketers are urged to address more layers and types of knowledge within a specific cultural context. This will encourage sustainability claims to be viewed within a specific wider setting and consumers will be able to draw on different types and layers of information during the decoding process of claims. With sustainability claims continuing to increase in the market environment, it can be assumed that consumers may not be knowledgeable of all the labelling developments across multiple industries/FMCGs. Companies can therefore provide a background to their sustainability claims and can both educate and help consumers understand the relevance and the importance of their messages.

This approach was found in certifications such as the Fair Trade label where consumers had more layers and types of knowledge (both concrete and abstract), which provided them the confidence needed to support the label. Consumers also used abstract and concrete knowledge when they lacked labelling knowledge, but again this was at time interpreted inconsistently with the original meaning of the label. This was the case for the decoding of company generated Type II claims and social cause claims.

Concrete knowledge is predominantly acquired through media attention and, thus, labels may not always be decoded in the ways they were original set out. In accordance with previous research this study concurs that the overall knowledge on labelling and eco labels in general terms is limited $[24,53]$ and only apparent in the case of a few certifications. This implies that consumers are, in a way, wanting more information about the individual schemes, who is behind them, and what they stand for, in order to guide their decision-making processes. In a similar manner, discussions throughout the focus groups emerged around the topic of "knowing the regulation". Consumers indicated that they feel they lack knowledge in terms of not only of labelling schemes, but also regulations and on-pack labelling requirements. This aspect has significant marketing implications for producers who need to absorb the cost of certification [67]. The negative perceptions and limited knowledge of Type II claims has negative spillover effects to Type I eco labels. This implies a risk of negative market perceptions of labelling snowballing to different types of labels. Similarly, consumers in this study expressed scepticism towards organic related labels used in the food industry, which confirms previous findings $[67,68]$. A justification 
that can be provided for the scepticism is the fact that the core values these labels stand for cannot necessarily be verified. Throughout the literature a common suggestion to overcome this challenge is to create "a certification they can trust" [67]. However, Eden et al. [68] found that this is not always the case especially with UK consumers, who do not seem to trust third party assurance schemes. Finally, the findings agree with previous studies about the non-preference of consumers for organic products, demonstrating the lack of support $[69,70]$ given their higher price.

Consumers' lack of labelling knowledge is not a new phenomenon in the literature [51,53]. In accordance with past research, this study concurs that consumer knowledge of labelling is low. However, after exploring consumers' perceptions of different types of labelling and their knowledge it became apparent that environmental knowledge alone is not enough to enable consumers to understand the "labelling-scape". This corresponds with previous studies that stressed the weakness of the link between environmental knowledge and behaviour [42,50]. This research found that consumers decode various sustainability claims through environmental knowledge (abstract and concrete), political, branding, and labelling knowledge. These layers of knowledge make it possible for them to decode and make sense of the plethora of claims in the market.

Thus, consumers mentioned the political environment and regulation when they discussed Type I eco labels and certifications implying that the wider context of these labels needs to be considered by both policy makers and marketers. Consumers also referred to their brand and marketing knowledge especially when decoding Type II claims. In this case when their environmental knowledge was limited they referred to the price, the quality, the product sector and the brand. Marketers communicating environmental information need to consider the wider relevance of the logo to the product sector as well as the brand itself. Consumers when lacking environmental knowledge take a more visual approach and thus label design and wording play a vital role. Policy makers and marketers need to take a more holistic and integrated approach in labelling as part of their wider brand offering and equip consumers with the knowledge they require to make sense and understand the labels. Even though design has received great attention in the banding literature, there are not any well-known studies on labelling and certification design and consumers' perceptions. This study covered this gap in the literature by indicating that in many cases the certification and label designs themselves can be seen as a considerable obstacle to decoding the messages.

The researchers found that the decoding process is challenging which in turn frustrates consumers and results in a negative spillover to labelling as a practice. This fact has marketing implications, as marketers need to communicate labelling effectively by aligning it with the political, regulatory and national background and particularities. This important link between the brand and environmental knowledge has been looked at in the literature where it was argued that knowledge on environmental issues tends to create not only awareness for particular brands, but also raises positive attitudes towards these brands, which is enhanced through the use of environmental labels [51]. This further highlights the importance of connecting the brand with the label and the environmental knowledge behind it. At this point it should be noted that this does not imply that by providing complex environmental scientific information marketers gain consumer preference. As indicated in the literature consumers have difficulty in understanding complex environmental problems and information [51], which is supported in this study. However, it was clear that a lack of basic explanation and relevance of the labels to the wider environmental and/or social context can cause quite a negative consumer reaction. In other words, as 
much as providing complex and scientific information may overestimate consumers' decoding potential the opposite can be equally risky. D’Souza et al. [51], for instance, argue that on the one hand consumers have to be educated to understand the general impact of the product on the environment, but on the other hand consumers have to gain the knowledge that products are produced in an environmentally friendly way. This implies that the role of consumer education is crucial. The researchers also found that ecological literacy in various instances enabled consumers to decode the labels they encountered. This was especially the case when consumers felt very passionate about certain issues such as forests, the sea, and animals. These consumers with higher ecological literacy seemed to be more receptive to particular claims. In this case, labels are seen as tools that protect elements of the natural environment that consumers feel passionate about.

\section{Conclusions}

This study highlighted the complexity of consumer knowledge in decoding labels on FMCGs, and raised important issues for marketers looking to improve and support their labelling practices. This complexity in decoding information falls under the complexity of sustainable consumption decision making as argued by a number of researchers in the past [64,71-73]. In other words we argue that consumers will never be/or should not be up to date with current and fast changing labelling developments but they have a right to truthful, useful and substantiated on-pack information. This can be facilitated by the companies who are adopting the labels by providing consumers with a wider environmental and/or social context to the label and by addressing additional surrounding layers of knowledge. As it currently stands, companies have high expectations that consumers will understand their on-pack messages without providing them the tools to do so. This creates negative feelings on the part of the consumers about labelling itself.

Different types of labels demand an integrated approach of different layers of knowledge from consumers if they are to be successful, and help to promote sustainable consumption. Based on the findings, it is clear that marketers need to examine and support their labels through the same wells of knowledge used by consumers, so that all parties can be confident of what labels are communicating about a product and its environmental and/or social impact. Only by re-examining the whole process and context of encoding and decoding will labels do what they are intended to do: facilitate sustainable consumption.

This study took a country level approach and highlighted the main differences in consumers' encoding process. Future research can focus on a micro level approach within a country (e.g., compare younger consumers to empty nesters) or between countries (e.g., compare empty nesters across countries) as this would add to our understanding of the complexity of consumers' decoding strategies.

\section{Acknowledgments}

The authors are grateful to Unilever (Home and Personal Care, Europe) who funded the original data collection for this study for their generous support and encouragement. 


\section{Author Contributions}

Dr Alevizou undertook the datra collection and data analysis for this paper. In addition, she led the writing process, supported by both Dr Oates and Prof McDonald who worked with her on editing alternating drafts. All authors read and approved the final manuscript.

\section{Conflicts of Interest}

The authors declare no conflict of interest.

\section{References}

1. Peattie, K. Green Marketing; Longman: London, UK, 1992.

2. Ottman, J.A. Green Marketing: Challenges and Opportunities; NTC Business Books: Lincolnwood, IL, USA, 1993.

3. Mendleson, N.; Polonsky, M.J. Using strategic alliances to develop credible green marketing. J. Consum. Market. 1995, 12, 4-18.

4. Gertz, R. Eco-labelling-A case for deregulation? Law Probab. Risk 2005, 4, 127-141.

5. Hoek, J.; Roling, N.; Holdsworth, D. Ethical claims and labelling: An analysis of consumers' beliefs and choice behaviours. J. Market. Manag. 2013, 29, 772-792.

6. Saha, M.; Darnton, G. Green Companies or Green Con-panies: Are Companies Really Green, or Are They Pretending to Be? Bus. Soc. Rev. 2005, 110, 117-157.

7. Ottman, J. The New Rules of Green Marketing: Strategies, Tools, and Inspiration for Sustainable Branding; Berrett-Koehler Publishers: San Francisco, CA, USA, 2011.

8. Belz, F.K.; Peattie, K. Sustainability Marketing a Global Perspective, 2nd ed.; John Wiley and Sons Ltd.: Glasgow, UK, 2012.

9. Martin, D.; Schouten, J. Sustainable Marketing; Prentice Hall: Boston, MA, USA, 2012.

10. Coddington, W. Environmental marketing's new relationship with corporate environmental management. Total Qual. Environ. Manag. 1993, 2, 297-302.

11. Ottman, J. Green Marketing: Opportunity for Innovation, 2nd ed.; Business Books: London, UK, 1998.

12. De Pelsmacker, P.; Driesen, L.; Rayp, G. Do Consumers Care about Ethics? Willingness to Pay for Fair-Trade Coffee. J. Consum. Aff. 2005, 39, 363-385.

13. Pieniak, Z.; Aertsens, J.; Verbeke, W. Subjective and objective knowledge as determinants of organic vegetables consumption. Food Qual. Prefer. 2010, 21, 581-588.

14. Berry, H.; McEachern, M.G. Informing Ethical Consumers; Harrison, R., Newholm, T., Shaw, D., Eds.; Sage Publications: London, UK, 2005; pp. 69-87.

15. Koos, S. Varieties of environmental labelling, market structures, and sustainable consumption across Europe: A comparative analysis of organizational and market supply determinants of environmental-labelled goods. J. Consum. Pol. 2011, 34, 127-151.

16. Polonsky, M.; Bailey, J.; Baker, H.; Basche, C.; Jepson, C.; Neath, L. Communicating environmental information. Are marketing claims on packaging misleading? J. Bus. Ethics 1998, 17, 281-294. 
17. Rubik, F.; Frankl, P. The Future of Eco-labelling: Making Environmental Product Information Systems Effective; Greenleaf Publishing: Sheffield, UK, 2005.

18. Boström, M.; Klintman, M. Eco-standards, Product Labelling and Green Consumerism; Palgrave Macmillan: Basingstoke, UK, 2011.

19. Stokes, A.; Turri, A.M. Consumer perceptions of carbon labeling in print advertising: Hype or effective communication strategy? J. Market. Comm. 2013, 21, 300-315.

20. Drumwright, M.E. Company Advertising with a Social Dimension: The Role of Noneconomic Criteria. J. Market.1996, 60, 71-87.

21. Carlson, L.; Grove, S.; Kangun, N. A content analysis of environmental advertising claims: A matrix method approach. J. Advert. 1993, 22, 27-40.

22. Banerjee, S.B. Corporate environmentalism and the greening of strategic marketing: Implications for marketing theory and practice. In Greener Marketing. A Global Perspective on Greening Marketing Practice; Charter, M., Polonsky, M.J., Eds.; Aizlewood’s Mill: Greenleaf, UK, 1998; pp. 16-40.

23. Harrison, R.; Newholm, T.; Shaw, D. The Ethical Consumer; SAGE Publications: London, UK, 2005.

24. Nocella, G.; Boecker, A.; Hubbard, L.; Scarpa, R. Eliciting Consumer Preferences for Certified Animal-Friendly Foods: Can Elements of the Theory of Planned Behavior Improve Choice Experiment Analysis? Psychol. Market. 2012, 29, 850-868.

25. Peattie, K. Environmental Marketing Management: Meeting the Green Challenge; Financial Times Management: London, UK, 1995.

26. Maloney, M.P.; Ward, M.P. Ecology: Let's hear from the people: An objective scale for the measurement of ecological attitudes and knowledge. Am. Psychol. 1973, 28, 583-586.

27. Hines, J.M.; Hungerford, H.R.; Tomera, A.N. Analysis and synthesis of research on responsible environmental behavior: A meta-analysis. J. Environ. Educ. 1987, 18, 1-8.

28. Martin, B.; Simintiras, A.C. The impact of green product lines on the environment: Does what they know affect how they feel? Market. Intell. Plann. 1995, 13, 16-23.

29. Grob, A. A structural model of environmental attitudes and behaviour. J. Environ. Psychol. 1995, 15, 209-220.

30. Cheah, I.; Phau, I. Attitudes towards environmentally friendly products: The influence of ecoliteracy, interpersonal influence and value orientation. Market. Intell. Plann. 2011, 29, 452-472.

31. Schahn, J.; Holzer, E. Studies of individual environmental concern the role of knowledge, gender, and background variables. Environ. Behav. 1990, 22, 767-786.

32. Fryxell, G.E.; Lo, C.W. The influence of environmental knowledge and values on managerial behaviours on behalf of the environment: An empirical examination of managers in China. J. Bus. Ethics 2003, 46, 45-69.

33. Golley, F.B. A Primer for Environmental Literacy; University Press: Yale, UK, 1998.

34. Orr, D.W. Ecological Literacy: Education and the Transition to A Postmodern World; Suny Press: Albany, NY, USA, 1992.

35. Morrone, M.; Mancl, K.; Carr, K. Development of a metric to test group differences in ecological knowledge as one component of environmental literacy. J. Environ. Educ. 2001, 32, 33-42.

36. Disinger, J.F.; Roth, C.E. Environmental Literacy (ERIC Digest EDO-SE-92-1); Clearinghouse for Science, Mathematics, and Environmental Education: Columbus, OH, USA, 1992. 
37. Hungerford, H.R.; Volk, T.L. Changing learner behavior through environmental education. J. Environ. Educ. 1990, 21, 8-21.

38. Environmental Protection Agency (EPA). Environmental labeling: Issues, policies, and practices worldwide. Available online: http://www.epa.gov/oppt/epp/pubs/wwlabel3.pdf (accessed on 2 February 2015).

39. Laroche, M.; Bergeron, J.; Barbaro-Forleo, G. Targeting consumers who are willing to pay more for environmentally friendly products. J. Consum. Market. 2001, 18, 503-520.

40. Chan, R.Y.K. Environmental attitudes and behavior of consumers in China: Survey findings and implications. J. Int. Consum. Market. 1999, 11, 25-52.

41. Ajzen, I.; Fishbein, M. Understanding Attitudes and Predicting Social Behaviour; Prentice-Hall: Cliffs, NJ, USA, 1980.

42. Mostafa, M.M. Gender differences in Egyptian consumers' green purchase behaviour: The effects of environmental knowledge, concern and attitude. Int. J. Consum. Stud. 2007, 31, 220-229.

43. Tilikidou, I. The effects of knowledge and attitudes upon Greeks' pro-environmental purchasing behaviour. Corp. Soc. Responsib. Environ. Manag. 2007, 14, 121-134.

44. Vining, J.; Ebreo, A. What makes a recycler? A comparison of recyclers and nonrecyclers. Environ. Behav. 1990, 22, 55-73.

45. Wells, V.K.; Ponting, C.A.; Peattie, K. Behaviour and climate change: Consumer perceptions of responsibility. J. Market. Manag. 2011, 27, 808-833.

46. De Boer, J. Sustainability labelling schemes: The logic of their claims and their functions for stakeholders. Bus. Strategy Environ. 2003, 12, 254-264.

47. Brucks, M. The effects of product class knowledge on information search behavior. J. Consum. Res. 1985, 12, 1-16.

48. Dodd, T.H.; Laverie, D.A.; Wilcox, J.F.; Duhan, D.F. Differential effects of experience, subjective knowledge, and objective knowledge on sources of information used in consumer wine purchasing. J. Hospit Tourism Res. 2005, 29, 3-19.

49. Thøgersen, J. Psychological determinants of paying attention to eco-labels in purchase decisions: Model development and multinational validation. J. Consum. Pol. 2000, 23, 285-313.

50. Pedersen, E.R.; Neergaard, P. Caveat emptor_-Let the buyer beware! Environmental labelling and the limitations of "green" consumerism. Bus. Strategy Environ. 2006, 15, 15-29.

51. D’Souza, C.; Taghian, M.; Lamb, P. An empirical study on the influence of environmental labels on consumers. Corp. Comm. Int. J. 2006, 11, 162-173.

52. Parkinson, T.L. The Role of Seals and Certifications of Approval in Consumer Decision-Making. J. Consum. Aff. 1975, 9, 1-14.

53. D’Souza, C.; Taghian, M.; Lamb, P.; Peretiatko, R. Green decisions: Demographics and consumer understanding of environmental labels. Int. J. Consum. Stud. 2007, 31, 371-376.

54. Bulkeley, H. Common knowledge? Public understanding of climate change in Newcastle, Australia. Publ. Understand. Sci. 2000, 9, 313-334.

55. Majoras, D.P. Carbon Offset Workshop: Opening Remarks, FTC, Washington, DC. Available online: www.ftc.gov/speeches/majoras/080108carbonow.pdf (accessed on 25 February 2015). 
56. Polonsky, M.J.; Vocino, A.; Grau, S.L.; Garma, R.; Ferdous, A.S. The impact of general and carbon-related environmental knowledge on attitudes and behaviour of US consumers. J. Market. Manag. 2012, 28, 238-263.

57. Malhotra, N.K.; Agarwal, J.; Peterson, M. Methodological issues in cross-cultural marketing research: A state-of-the-art review. Int. Market. Rev. 1996, 13, 7-43.

58. Oates, C.J. The use of focus groups in social science research. In Research Training for Social Scientists. A Handbook for Postgraduate Researchers; Burton, D., Ed.; SAGE Publications: London, UK, 2000.

59. Asbury, J.E. Overview of focus group research. Qual. Health Res. 1995, 5, 414-420.

60. Morgan, D.L. Focus Groups as Qualitative Research; Sage: London, UK, 1986.

61. Krueger, R.A. Focus Groups: A Practical Guide for Applied Research, 2nd ed.; Sage Publications: Thousand Oaks, CA, USA, 1994.

62. Kinnear, T.; Taylor, R.J. Marketing Research an Applied Approach, 4th ed.; McGraw-Hill Inc.: New York, NY, USA, 1996.

63. Krueger, R.A. Focus Groups: A Practical Guide for Applied Research, 1st ed.; Sage: Newbury Park, CA, USA, 1988.

64. Alevizou, P.J. Sustainability Claims on FMCGs, Consumers' Perceptions and Company Practice in the UK and in Greece. Ph.D. Thesis, University of Sheffield, Sheffield, UK, 2011.

65. Easterby-Smith, M.; Thorpe, R.; Jackson, P. Management Research, 3rd ed.; Sage Publications: London, UK, 2008.

66. Strauss, A.; Corbin, J. Basics of Qualitative Research, 2nd ed.; Sage: London, UK, 1998.

67. Gerrard, C.; Janssen, M.; Smith, L.; Hamm, U.; Padel, S. UK consumer reactions to organic certification logos. Br. Food J. 2013, 115, 727-742.

68. Eden, S.; Bear, C.; Walker, G. Mucky carrots and other proxies: Problematising the knowledge-fix for sustainable and ethical consumption. Geoforum 2008, 39, 1044-1057.

69. Batte, M.T.; Hooker, N.H.; Haab, T.C.; Beaverson, J. Putting their money where their mouths are: Consumer willingness to pay for multi-ingredient, processed organic food products. Food Pol. 2007, 32, 145-159.

70. Cottingham, M.; Winkler, E. The Organic Consumer. In The Handbook of Organic and Fair Trade Food Marketing; Wright, S., McCrea, D., Eds.; Blackwell Publishing Ltd.: Oxford, UK, 2007.

71. Moisander, J. Motivational complexity of green consumerism. Int. J. Consum. Stud. 2007, 31, 404-409.

72. McDonald, S.; Oates, C.J.; Alevizou, P.J.; Young, C.W.; Hwang, K. Individual strategies for sustainable consumption. J. Market. Manag. 2012, 28, 445-468.

73. Fuentes, C. Managing green complexities: Consumers' strategies and techniques for greener shopping. Int. J. Consum. Stud. 2014, 38, 485-492.

(C) 2015 by the authors; licensee MDPI, Basel, Switzerland. This article is an open access article distributed under the terms and conditions of the Creative Commons Attribution license (http://creativecommons.org/licenses/by/4.0/). 